\title{
El nuevo cogito de E. Sosa: juicio e imagen en la geografía lógica del sueño
}

\author{
Modesto M. Gómez Alonso \\ Universidad Pontificia de Salamanca \\ Facultad de filosofía \\ modestomga@hotmail.com
}

1. De entre los numerosos escenarios escépticos que configuran la agenda de la epistemología, hay uno que destaca especialmente: el argumento del sueño. No se trata tan solo de una hipótesis a cuya indudable fuerza retórica se añada su relativa transparencia lógica. Además, posee una serie de rasgos cuya conjunción le otorga un papel irreemplazable en el proyecto epistemológico: (i) A diferencia de las posibilidades no eliminadas pero eliminables a las que recurre el escepticismo neo-pirrónico ${ }^{1}$, la hipótesis del sueño extiende la duda hasta alcanzar nuestras creencias perceptivas básicas, esto es, creencias nucleares («Estoy sentado, junto a la mesa, leyendo esta ponencia») sobre las que una duda empírica resulta inefectiva e ininteligible. (ii) Se trata de un escenario global, es decir, de una hipótesis que si es capaz de proporcionar una razón para dudar de la experiencia presente entonces, porque si pudiese estar soñando ahora, podría estar soñando en

\footnotetext{
${ }^{1}$ «[...] me parece que tan pronto como consideramos la posibilidad de que lo que parecen cebras sean realmente mulas pintadas [Fogelin discute un escenario de filiación neo-pirrónica propuesto por Fred Dretske], esto solo basta para que retiremos la declaración no cualificada de que realmente sabemos que los animales que vemos son cebras. Lo que sugiero es que barajar dichas posibilidades es suficiente para elevar nuestros niveles de escrutinio» (Fogelin 1994; 83). Los escenarios pirrónicos son, por lo tanto, mecanismos que generan la duda «desde la sola reflexión» (Fogelin 1994; 99) y que apelan a hipótesis que, aunque refutables, todavía no han sido refutadas. A partir de ahora, CSMy AT, respectivamente, seguidos de volumeny página.
} 
cualquier momento dado, también proporciona una razón para dudar de cualesquiera experiencia a la que apele con el fin de eliminar dicha posibilidad. En este sentido, se trata de una hipótesis que, cuestionando nuestro sistema de evidencias al completo, no puede refutarse mediante el empleo de evidencias a las que el propio argumento neutraliza. (iii) Nos encontramos con una hipótesis que, en contraste con otros escenarios ya consolidados: el Dios engañador cartesiano, el cerebro en la probeta..., que, basándose bien en «opiniones» (Cottingham 1984; 14. Adam 1996; 21) $)^{2}$ bien en narraciones alternativas diseñadas en el laboratorio epistemológico, constituyen simples posibilidades en abstracto, recurre a elementos (los sueños) que forman parte de nuestra vida ordinaria. De este modo, se trata de una hipótesis que, enraizada en la experiencia corriente, es tan natural como inquietante. (iv) Finalmente, el alcance del argumento tradicional es limitado: pone en entredicho nuestra imagen del mundo sin cuestionar por ello nuestra capacidad de juicio, esto es, sin invalidar la autoridad última de la razón y sin afectar al conocimiento introspectivo.

Un criterio para evaluar la importancia del argumento del sueño es la hostilidad que ha generado en la filosofía lingüística. Bouwsma intentó disolverlo, constatando que la gramática ordinaria incluye y exige la posibilidad de discernir los contenidos presentes en los estados de sueño y vigilia (ver Bouwsma 1982; 51-63). Malcolm, con el fin de concluir su sinsentido, denunció su presupuesto básico: la existencia de estados de consciencia específicos a los que pueda denominarse «sueños» (ver Malcolm 1962). De acuerdo con el discípulo de Wittgenstein los sueños ni poseen duración (ver Malcolm 1962; 78-9) ni son experiencias reales independientes de su narración que recordemos al despertar: soñar es «narrar un sueño» bajo la influencia de una fuerte impresión (ver Malcolm 1962; 85-6), el sueño es algo que construimos en la vigilia al contarlo, una ficción y no un acontecimiento, dormir y ser sujeto de experiencias conscientes constituyen categorías exclusivas. Sin embargo, ninguna de estas estrategias deflacionistas resulta convincente. La

${ }^{2}$ A partir de ahora, CSM y AT, respectivamente, seguidos de volumen y página. 
primera, porque, además de presuponer una concepción verificacionista del significado extremadamente improbable, olvida que el escéptico, en lugar de construir arbitrariamente una noción artificial de «sueño», opera de acuerdo con los criterios de la gramática ordinaria, criterios de cuya aplicación se concluye la imposibilidad de discernir sueño y vigilia. En este sentido, el escéptico nos muestra lo que deberíamos decir de acuerdo con nuestras propias normas, emplea nuestras reglas para denunciar nuestras prácticas. La segunda, porque, contra-intuiti$v a$, ejemplifica la tendencia de algunos filósofos sofisticados a disolver problemas epistemológicos a través de respuestas desproporcionadas. Negar realidad a los sueños con el fin de evitar el problema de la indiscernibilidad es análogo a suscribir el idealismo con el propósito de evitar el escepticismo: se inhibe una cuestión genuina reemplazándola por una concepción que atenta directamente contra el sentido común.

Inmune a las tendencias relativistas, naturalistas y deflacionarias predominantes en la filosofía anglosajona de las últimas décadas, Ernest Sosa ha devuelto al argumento del sueño su prioridad epistemológica (ver Sosa 2007; 1-43). Reconociendo su sentido prima facie, subrayando su cercanía a la vida ordinaria y haciendo patente su papel en el proceso de justificación reflexiva de nuestras creencias, ha demostrado que el único medio para superar el argumento cartesiano es, encarándolo directamente, su refutación. El reto escéptico no puede ser ni ignorado ni disuelto: exige su resolución mediante un uso riguroso de la racionalidad. Curiosamente, dicha refutación será el resultado de su extensión. En otras palabras: Sosa no sólo ha rehabilitado el problema cartesiano en el contexto analítico contemporáneo, también ha propuesto un procedimiento novedosísimo para superarlo, una estrategia que, otorgando al argumento un alcance escéptico insospechado, logra así, primero, reducir hasta tal punto su verosimilitud que el peligro de error se minimiza (y, de este modo, se mitiga «nuestra exposición» (Sosa 2007; 3) al argumento), más tarde, refutarlo.

2. El desarrollo de la estrategia de Sosa exige una explicación sucinta de algunas de las distinciones que estructuran su modelo epistemológico: la epistemología virtuosa. En concreto, de la distinción entre cono- 
cimiento animal y conocimiento reflexivo (ver Sosa 2007; 22-43), y entre creencia apta, creencia segura y creencia cierta (ver Sosa 2007; 28-36).

La noción de «conocimiento animal» equivale al concepto cartesiano de cognitio (ver Sosa 2009; 135-53), remite a una concepción de las declaraciones cognitivas de acuerdo a la cual $x$ sabe que $p$ si y sólo si se cumplen tres condiciones: (i) que lo que cree sea verdad, (ii) que su creencia se encuentre justificada y, (iii) que, dadas las circunstancias que rodean su declaración cognitiva (circunstancias que el sujeto epistémico puede ignorar), su éxito no sea fortuito. Lo que nos interesa subrayar ahora es que estas condiciones pueden satisfacerse con independencia de que $x$ sepa que se satisfacen, o, lo que es igual, que para que alguien sepa algo no tiene por ello que saber que lo sabe, que no es necesario eliminar las hipótesis escépticas para que sea verdad que uno sabe. Obviamente, este concepto reivindica un modelo externalista según el cual el conocimiento ni admite ni requiere una intelectualización excesiva.

El «conocimiento reflexivo» se corresponde, por el contrario, a la scientia cartesiana, esto es, a las condiciones que han de cumplirse, no para que alguien sepa, sino para que sea verdad que sabe que sabe. Aquí se evalúa nuestro derecho a decir que sabemos, la legitimidad de nuestras creencias por mucho que éstas (sin nosotros saberlo) sean correctas o constituyan «conocimiento animal». Se trata, por tanto, del orden de razones, y no del de causas. Lo que implica que es el espacio natural tanto de los escenarios globales como del proyecto epistemológico.

Esta distinción permite ubicar el argumento del sueño en el lugar que le corresponde. Lo que éste cuestiona no es nuestro conocimiento animal, sino nuestro conocimiento reflexivo. Así, sentido común e investigación epistemológica se reconcilian. Con Moore, podemos saber que tenemos manos aunque no podamos refutar el argumento del sueño. Con Descartes, no sabremos que sabemos que las tenemos mientras no lo refutemos. Consiguientemente, el argumento del sueño, más que atentar contra nuestro conocimiento, pone en entredicho nuestra capacidad para defenderlo en el ámbito de la reflexión (ver Sosa 2007; 34).

En la terminología técnica acuñada por Sosa, «creencia apta» y «conocimiento animal» son términos sinónimos. Sin embargo, «creen- 
cia segura» $\mathrm{y}$ "creencia cierta» se refieren a grados de conocimiento reflexivo, es decir, a dos niveles de justificación epistémica evaluables de acuerdo con el criterio de resistencia a los escenarios escépticos radicales. Una creencia será segura en el supuesto de que su falsedad, aunque lógicamente posible, sea sumamente improbable. La seguridad de una creencia implica, por tanto, cierta fragilidad. No es una seguridad absoluta, sino relativa. Por otra parte, una creencia será cierta «si y sólo si en el caso de que $p$ no fuese verdadera, (el sujeto epistémico) no podría creer que $p$ » (Sosa 2007; 25), es decir, en el supuesto de que la verdad de $\mathrm{p}$ sea una condición necesaria para creer que $\mathrm{p}$. «Creencia cierta» equivale así a seguridad absoluta, incorregibilidad, creencia basada en razones concluyentes e imposibilidad de razones escépticas que pongan en entredicho una creencia dada. El término recoge el ideal cartesiano de un punto arquimédico más allá del alcance del escepticismo hiperbólico.

El argumento del sueño no erosiona la aptitud de nuestras creencias, sino su seguridad y su certeza. Pero, dado que los requisitos epistémicos de las dos últimas categorías difieren cualitativamente, el procedimiento de Sosa será gradual. En un primer momento, intentará garantizar la seguridad de nuestras creencias perceptivas básicas, esto es, tratará de mostrar que, pese a la posibilidad del sueño, que tengo manos es un conocimiento tan seguro como el propio Cogito. Sólo en un segundo momento, y con el fin de destilar a partir del conocimiento altamente probable un conocimiento infalible, recurrirá a un argumento por reducción al absurdo del que se sigue que el sueño no es tan siquiera una posibilidad, y que, por consiguiente, las creencias perceptivas nucleares son análogas a intuiciones, esto es, a pensamientos cartesianos, pensamientos de los que no podemos dudar sin descubrir que dicha duda resulta ininteligible. En este sentido, Sosa defiende una versión extendida del Cogito, equiparando la indubitabilidad de nuestro conocimiento del mundo externo a la indubitabilidad de la primera certeza. «Podemos afirmar con idéntica certeza "Pienso, luego estoy despierto" y "Pienso, luego existo"» (Sosa 2007; 20).

3. El blanco de la argumentación de Sosa es la «concepción ortodoxa» (Sosa 2007; 2) del sueño, una representación que el autor norteameri- 
cano atribuye a Descartes y a la que denomina «modelo alucinatorio». Tres rasgos constituyen esta cartografía conceptual de los sueños: (i) La tesis de acuerdo a la cual los sueños incluyen, además de imágenes y sensaciones, creencias, argumentos, intenciones y actos de asentimiento, negación y suspensión intelectual del juicio. En este sentido, el contenido de los sueños es denso: en el sueño se reproducen operaciones perceptivas, volitivas e intelectuales. (ii) La señalización de que, aunque lo que ocurre dentro del sueño no se encuentra ni causal ni epistémicamente vinculado a lo que sucede en la realidad (todo lo que acaece en el sueño podría ser falso), la totalidad de los estados psicológicos y de las operaciones volitivas e intelectuales que el sujeto soñante realiza o padece en el sueño son atribuibles a él mientras sueña, es decir, son realmente acciones, omisiones, pasiones o deliberaciones del individuo que sueña, estados que el sueño no cuestiona en la medida en que lo trascienden. El trueno que escucho en sueños no es real, pero el temor con el que lo vivo en el sueño es un estado real que sufro, no sólo dentro del sueño, sino mientras sueño. Del mismo modo, aunque las creencias que formo en sueños sean falsas, no es falso que sean mis creencias con independencia de que las crea en el sueño. (iii) El hecho, deducible de las dos primeras tesis, de que el argumento del sueño es limitado: no afecta al conocimiento introspectivo, a los estados psicológicos del individuo que, soñando que siente, piensa y razona, realmente siente, razona y piensa.

De acuerdo con Sosa, la segunda tesis de la «concepción ortodoxa» es falsa (y, por tanto, también la tercera, que se deduce de ella): los estados psicológicos del sujeto en el sueño (en tanto que protagonista del sueño o punto focal interno de lo que acaece en el sueño) no son atribuibles al sujeto mientras sueña (al sujeto en tanto que espectador de lo que se representa en sueños). Esta escisión absoluta entre los contenidos del sueño y la realidad se basa, fundamentalmente, en tres argumentos: (i) Si las creencias en las que el sujeto sueña fuesen creencias del sujeto que sueña, éste poseería dos sistemas contradictorios de creencias: por una parte, todas aquellas creencias que ha formado durante su vida diurna, y que, aunque sin actualizar, preserva mientras sueña; y todas aquellas otras que forma en el sueño. Este 
supuesto implicaría irracionalidad, una irracionalidad que sólo puede evitarse postulando que las creencias que aparecen en sueños no son creencias del sujeto soñante. (ii) Un argumento moral que señala que, en la medida en que si las opciones que el sujeto toma dentro del sueño fuesen decisiones atribuibles al sujeto en absoluto éste sería responsable de lo que hace en el sueño, el «modelo alucinatorio» implicaría imputarnos culpa y responsabilidad morales por lo que soñamos que realizamos. Una alucinación no excluye responsabilidad moral, pues, aunque las creencias de $x$ sean falsas, sus decisiones son reales. Sin embargo, los sueños no son análogos a alucinaciones, al menos en este aspecto: lo que decidimos soñando no nos es imputable (Sosa 2007; 7). Por eso, lo que Sosa subraya aquí es el conflicto entre las implicaciones de la concepción tradicional y la «gramática moral» del sueño. (iii) La constatación de que, porque las mismas razones que hacen del argumento del sueño una herramienta escéptica que nos disocia del mundo externo generan un divorcio entre el sujeto epistémico y sus creencias en tanto que posibles objetos de representación en sueños, el modelo tradicional, limitando el escepticismo del sueño, contradice el presupuesto básico que posibilita la duda respecto a nuestras creencias perceptivas nucleares. Si todo lo que aparece dentro del sueño puede ser, por eso mismo, falso; del hecho de que podamos estar soñando en que creemos, asentimos o pensamos se sigue que puede ser falso que pensemos, que creamos o que asintamos. En otras palabras: al igual que si pudiese estar soñando en que estoy en esta sala podría ser falso que estuviese en ella, si estuviese soñando en que pienso no estaría realmente pensando. Los contenidos del sueño son apariencias. Del postulado de que las operaciones intelectuales y volitivas pueden ser reproducidas en sueños se deduce que también pueden ser apariencias, $\mathrm{y}$, por consiguiente, que si pudiese estar soñando ahora no podría atribuirme creencias ni siquiera a mí mismo. La posibilidad del sueño no sólo nos escinde del mundo externo, sino de nosotros mismos. Bien pensado, este escenario se extiende hasta alcanzar al propio Cogito.

Dos objeciones se desarrollan «naturalmente» a partir de las reflexiones previas: (i) Señalando que los estados psicológicos en los que 
el sujeto sueña no le son en realidad atribuibles, ¿no está sugiriendo Sosa que los sueños no son experiencias reales, y que, por tanto, soñar, más que constituir un estado específico de la consciencia, es el nombre con el que denotamos un modo específico de narración?, ¿y no implica eso suscribir la concepción deflacionista y contra-intuitiva de Malcolm? (ii) ¿No está Sosa defendiendo una versión hiperbólica de escepticismo, una que, en vez de salvaguardar la verdad de nuestras creencias apelando al hecho último del significado, erosiona el significado extendiendo el alcance del argumento del sueño? En otras palabras: ¿cómo puede la extensión del escepticismo reducir su verosimilitud?

A la primera cuestión Sosa responde proponiendo una concepción alternativa de los sueños: el modelo imaginativo (Sosa 2007; 7-8). Las creencias en las que el sujeto sueña no son creencias del sujeto que sueña, pero de ahí no se deduce que el sujeto no se perciba a sí mismo barajando esas creencias dentro del sueño, esto es, que no sea sujeto de las experiencias fenoménicas (perceptos) que constituyen el sueño. El sujeto percibe realmente determinadas imágenes, se sitúa frente a lo que sucede en el sueño de forma análoga a como se sitúa frente a una película: viendo sin creer, percibiendo realmente sin identificarse con las creencias, acciones e intenciones que percibe (y por mucho que dichas intenciones le sean atribuibles dentro del sueño). De este modo, las imágenes del sueño son predicables respecto al sujeto mientras sue$\tilde{n} a$, y así se garantiza la realidad de la consciencia soñante sin que se limite el escepticismo. De otra forma: si el sujeto sueña que piensa no piensa, pero al menos es indudable, no que juzga que piensa, sino que percibe que piensa, o que, aunque sea falso que piensa, le parece estar pensando. Tal como hicieron los escépticos antiguos, los juicios pueden interpretarse no-epistémicamente, como apariencias carentes de fuerza racional. El problema es que, en la medida en que dicha predicación exige una concepción epistémicamente fuerte de la capacidad racional, es decir, en que el sujeto puede concluir que al menos es verdad que le parece estar pensando únicamente si de hecho está realmente pensando (si, por tanto, la apariencia de juicio es juicio real), cosa que el argumento del sueño le impide asegurar, los límites del sueño carecen 
de relevancia epistemológica: la certeza requiere mucho más que la percepción de que se está pensando. Que me parezca que juzgo no sólo no implica que juzgue, sino que me impide juzgar que me parece que juzgo. Este meta-juicio es sólo una apariencia, y, por ello, algo que ni siquiera puedo categorizar como apariencia mientras su realidad no se encuentre garantizada.

El segundo problema se resuelve apelando a la noción de «creencia segura». Del hecho de que el argumento del sueño cuestione, además de nuestras creencias perceptivas, las operaciones racionales básicas y nuestra vida mental, se sigue: (i) que si realmente juzgase (por ejemplo, que sueño) no soñaría; (ii) que, por tanto, si es verdad que juzgo también es verdad que tengo dos manos; (iii) que, porque, aunque todavía no se haya demostrado con certeza que juzgo, dicha creencia es altamente segura, también son seguras (tan seguras como el propio Cogito) las creencias perceptivas básicas. En este sentido, el descubrimiento de que nuestras creencias perceptivas y el Cogito poseen idéntico estatus epistemológico resta verosimilitud al argumento del sueño. Su extensión implica su escasísima probabilidad. Paradójicamente, era en los límites del argumento donde radicaba su fuerza. Ilimitado, el argumento pierde en intensión lo que gana en extensión. Por eso, podría decirse que Sosa, reinterpretando tanto el alcance como el significado del argumento del sueño, recupera la seguridad de nuestras creencias perceptivas. El argumento escéptico no pone en duda su seguridad, sino su certeza.

Baste, finalmente, señalar que Sosa recupera la certeza tanto del conocimiento introspectivo como del conocimiento del mundo externo empleando un argumento trascendental similar al esgrimido por Descartes en la «demostración» del Cogito al inicio de la Segunda Meditación. Lo que constata es que, para llegar a plantear el argumento del sueño el escéptico ha de considerar esa posibilidad, pero que del hecho de que la considere se sigue que está pensando, y, por consiguiente, que no está soñando. De este modo, y en la medida en que las condiciones que hacen posible la duda no son objeto de duda, la formulación del argumento del sueño es contradictoria, y, por ello, el escéptico cartesiano, por el solo hecho de proponer dicho escenario, se 
auto-refuta. Es evidente que este argumento por reducción al absurdo del escepticismo radical depende lógicamente de la imagen proporcionada por Sosa de la geografía conceptual del sueño, en concreto, de la tesis según la cual juicio y sueño son categorías exclusivas, esto es, del hecho de que la posibilidad del sueño erosiona nuestro conocimiento introspectivo. Sosa demuestra la certeza del Cogito y, por extensión, la indubitabilidad de nuestras creencias perceptivas nucleares. Sin embargo, la misma razón que hace especialmente admirable su tratamiento del problema: la estructura piramidal o fundacional de la argumentación; lo hace también vulnerable. Todo depende de la exclusividad de pensamiento y sueño. La problematicidad de este punto implicaría que el edificio al completo se tambalease.

4. Por último, querría mencionar algunas razones por las que, pese a su indudable ventaja respecto al «modelo tradicional» (al que, en mi opinión, Sosa refuta eficazmente), considero que su tratamiento del argumento escéptico no soluciona de forma definitiva el problema epistemológico planteado por Descartes. Me limitaré a plantear tres cuestiones:

(i) El hecho de que, tras haber demostrado que nuestras creencias perceptivas son tan seguras como el Cogito, Sosa construya un argumento trascendental cuya validez es independiente de la posibilidad de que estemos soñando (posibilidad que, a esa altura, todavía no se ha eliminado), muestra que implícitamente suscribe la tesis de la autonomía de la racionalidad, racionalidad cuyos contenidos se encuentran más allá del alcance de la hipótesis del sueño. Como uno de esos contenidos es el propio Cogito, la corrección de su demostración depende de la suposición de que el alcance del sueño es limitado, esto es, de la aceptación de la versión cartesiana del argumento y de la consiguiente eliminación tanto de su extensión como de la versión expandida del Cogito defendida por el filósofo. En otras palabras: si el argumento del sueño poseyese el alcance que Sosa le concede, la argumentación resultaría, ex hypothesi, 
inútil, y el escéptico, por mucho que no pudiese consolidar racionalmente sus conclusiones (mostrando que se trata de una posibilidad avalada por la razón), no podría ser refutado (lo que el escéptico habría mostrado es que la razón se autorefuta: si es confiable avala una posibilidad, la del sueño, de la que se sigue que no es confiable). Sosa se enfrentaría, en consecuencia, a un dilema: o un escepticismo total que se desprendería de la construcción no-epistémica de la totalidad de las apariencias implicada en la proyección del sueño a las operaciones racionales o la reducción del alcance del sueño que posibilitaría el desarrollo de la epistemología. Su filiación cartesiana le permitiría rechazar la primera (y demoledora) alternativa, filiación que, además, y tal como acabamos de señalar, ya contiene su propio argumento (o el simple hecho de que argumente). En otras palabras: porque la validez condicional del argumento trascendental no implica su validez absoluta, o bien se postula dicha validez absoluta, lo que significa limitar el alcance del argumento del sueño, o lo que se requiere es un procedimiento argumentativo capaz de romper el equilibrio escéptico, esto es, un tipo de argumento de cuya validez condicional se dedujese su validez absoluta, que impidiese al escéptico asentir al tiempo a las razones para dudar que esgrime y al argumento que las invalida y que cuestionase, más que los procedimientos, los contenidos a los que el escéptico recurre. En mi opinión, ni la así llamada «primera certeza» ni el argumento trascendental en el que se sostiene, cumplen estas condiciones. Es mérito de Descartes el haber mostrado que sólo la validez hipotética de la demostración de Dios implica su validez absoluta, y que, consecuentemente, el papel de Dios en epistemología es irreemplazable.

(ii) La estrategia de Sosa transforma a las creencias perceptivas básicas en contenidos pertenecientes a la estructura racional, y así, se compromete con una posición ultra-racionalista que hace de la experiencia un ámbito transparente a la razón pura. En mi opinión, esta posición conlleva una forma sofisticada de 
reduccionismo racionalista incapaz de dar cuenta tanto de la opacidad y de la contingencia de la experiencia como de la intimidad (no mediada por la reflexión) del sujeto con sus creencias perceptivas. De otro modo: es cierto que nuestras creencias naturales requieren justificación epistémica, pero dudo mucho que una perspectiva exclusivamente racional, que nos distancia de nosotros mismos en tanto que sujetos empíricos y para la que la particularidad fenoménica resulta ininteligible, pueda vincularnos reflexivamente con nuestras creencias fundamentales. Lo que se requiere es un fundamento para la falta de fundamentos, una estrategia capaz de garantizar la veracidad de nuestra experiencia sin renunciar a su opacidad intrínseca. El procedimiento cartesiano, que no reduce lo concebible a lo posible y que proporciona una justificación indirecta de lo que podemos legitimar sin comprender, podría garantizar un racionalismo sin reduccionismo, veracidad sin pérdida de intimidad.

(iii) Finalmente, el «modelo alucinatorio» ni es atribuible a Descartes ni es lógicamente necesario con el fin de suscribir la tesis del alcance limitado del argumento del sueño.

Lo primero, porque si tenemos en cuenta que en las Pasiones del alma, Descartes señala que las imágenes de los sueños son elementos no neurales (a diferencia de las percepciones, su causa última es el movimiento de los espíritus animales en el cerebro, no la estimulación sensorial transmitida a éste a través del sistema nervioso) causados exclusivamente por el cuerpo, y que, en consecuencia, los sueños son estados de la sustancia corporal comunes tanto a hombres como a animales y la vida consciente no es patrimonio de la res cogitans (ver AT XI: 344-345. CSM I: 336), constatamos que Descartes no suscribió la tesis según la cual creencias, intenciones y juicios son contenidos del sueño, esto es, la primera tesis que definía al «modelo alucinatorio». Paradójicamente, para Descartes los sueños sólo contienen imágenes y sensaciones, de lo que se deduce tanto que su paradigma posee rasgos análogos a los del «modelo imaginativo» como que la refutación de Sosa, correcta en lo 
que se refiere a la concepción tradicional, no puede aplicarse a la cartografía cartesiana.

Lo segundo, porque, para Descartes, la razón por la que, aunque mientras sueño mis juicios sean falsos, no es falso que juzgue, no es que el juicio que realizo en sueños sea también un juicio que realizo mientras sueño, sino que, precisamente porque los juicios no son contenidos del sueño, son acciones reales del sujeto que además sueña. Sosa tiene razón: si aceptamos un contenido denso en los sueños, el argumento se extiende hasta las operaciones racionales, y, por lo tanto, juicio y sueño son categorías exclusivas. Pero basta reemplazar ese contenido denso por un contenido débil (puramente corporal), para que podamos eliminar la tesis de la exclusividad sin comprometernos con la indefendible concepción tradicional. Curiosamente, aceptando la primera tesis del «modelo alucinatorio», la estrategia de Sosa es, en cierto sentido, parasitaria: sigue presa de la dinámica lógica creada por ese modelo.

No es mi propósito contrastar las cartografías de Sosa y de Descartes. Me basta constatar que hay modelos alternativos, y que, por consiguiente, la discusión no se reduce a dos opciones. Sólo quisiera subrayar un punto: la «concepción tradicional» se auto-refuta, pero la de Sosa, que, con el fin de defender la exclusividad de pensamiento y sueño, señala que «cuando soñamos, nuestro aparato cognitivo se encuentra desconectado» (Sosa 2007; 8), escinde al sujeto que sueña del sujeto que responde activamente a las imágenes del sueño, y así, no da cuenta del hecho de que, mientras soñamos, más que espectadores pasivos que se ven a sí mismos actuando en una pantalla, somos agentes cuyas decisiones y juicios, aunque causados por lo que percibimos en sueños, no forman parte del sueño, sino de nosotros mismos. Por eso pienso que hay cierta analogía entre alucinación y sueño, entre el escenario virtual de The Matrix y la hipótesis cartesiana: tanto en la realidad como en la ficción, es decir, con independencia de nuestro contexto, pensamos, juzgamos y somos sujetos de culpa y mérito. Respondiendo a sus percepciones (sean o no sean éstas falsas), el yo es responsable de sus actos. Esta dimensión epistémica y moral es salvaguardada por el modelo de Descartes. 
El descubrimiento del sujeto racional y moral que el argumento del sueño posibilita es la fuente de la pregunta cartesiana por excelencia: ¿cómo es posible un ser racional con creencias, alguien capaz de distanciarse de sí mismo y que, sin embargo, se encuentra íntimamente vinculado tanto al mundo como a su concepción del mundo?

El término ad quem de la epistemología es la antropología: el problema de la naturaleza dual del ser humano.

\section{BIBLIOGRAFÍA}

Adam, C.; Tannery, P. (eds.). (1996). Oeuvres de Descartes. Meditationes de Prima Philosophia (VII). Paris: J. Vrin.

Cottingham, J.; Stoothoff, R.; Murdoch, D. (eds.). (1984). The Philosophical Writings of Descartes (Volume II). Cambridge: Cambridge University Press.

Bouwsma, O. K. (1982). Descartes' Skepticism of the Senses. En O. K. Bouwsma, Philosophical Essays. Lincoln / London: University of Nebraska Press, 51-63.

Fogelin, R. J. (1994). Pyrrhonian Reflections on Knowledge and Justification. Oxford / New York: Oxford University Press.

Malcolm, N. (1962). Dreaming. London / New York: Routledge \& Kegan Paul.

Sosa, E. (2009), Reflective Knowledge. Apt Belief and Reflective Knowledge, Volume II (Oxford / New York: Oxford University Press).

Sosa, E. (2007), A Virtue Epistemology. Apt Belief and Reflective Knowledge, Volume I (Oxford / New York: Oxford University Press). 


\section{RESUMEN}

De acuerdo con la concepción ortodoxa (y supuestamente cartesiana), la indiscernibilidad entre sueño y sensación legitima un escepticismo extremo que desvincula nuestras experiencias de sus nexos causales y de sus fundamentos epistémicos. Ernest Sosa le opone un modelo imaginativo: mientras soñamos nuestro proceso cognitivo se encuentra desactivado. Ello implicaría, entre otras cosas: (i) atribuir al sujeto dos sistemas contradictorios de creencias; (ii) exigirle responsabilidad moral por lo que decide en sueños; y (iii) extender el escepticismo hasta el propio hecho de que se juzga y se piensa. Nos proponemos mostrar: (i) cómo el modelo de Descartes ni es identificable con la concepción ortodoxa ni se encuentra lógicamente alejado del modelo imaginativo; (ii) cómo permite detectar en la extensión sosiana del cogito una falacia por equivocación; (iii) finalmente, cómo permite salvaguardar la solidez del cogito, evitando al mismo tiempo comprometerse con una ontología fenomenista y con la recusación del escepticismo perceptivo.

Palabras clave: cogito, conocimiento reflexivo, creencia, juicio, modelo imaginativo, sensación.

\section{ABSTRACT}

According to the orthodox conception (supposedly Cartesian), the indiscernibility between sleep and feeling legitimizes an extreme skepticism that dissociates our experiences of their causal links and their epistemological foundations. Ernest Sosa opposes to it an imaginative model: while we dream our cognitive process is disabled. This would involve, among other things: (i) to attribute to the subject two contradictory belief systems; (ii) require moral responsibility for what you choose in a dream; and (iii), extend the skepticism until the very fact of judge and thought. We intend to show: (i) how the Cartesian model neither is identifiable with the orthodox nor logically away from the imaginative model; (ii) how it allows to detect in Sosa's extention of 
the cogito a fallacy by mistake; (iii) finally, that it can safeguard the soundness of the cogito, while avoiding committing to a phenomenalist ontology and the challenge of perceptive skepticism.

Key words: cogito, reflexive knowledge, belief, judgement, imaginative model, sensation. 